\title{
Biventricular repair of double-outlet right ventricle with noncommitted ventricular septal defect using intraventricular conduit
}

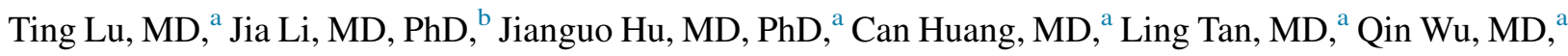
and Zhongshi $\mathrm{Wu}, \mathrm{MD}, \mathrm{PhD}^{\mathrm{a}}$

\section{ABSTRACT}

Objective: Biventricular repair of double-outlet right ventricle with noncommitted ventricular septal defect is preferred, but previously developed surgical procedures are complicated and associated with high mortality and morbidity. We developed a technique using an intraventricular conduit to connect the ventricular septal defect and the aorta in this anomaly in patients aged more than 2 years.

Methods: Thirty-one patients (age 2-23 years; median, 5.4) with double-outlet right ventricle with noncommitted ventricular septal defect underwent biventricular repair with intraventricular conduit. A 16-mm or 19-mm polytetrafluoroethylene (Gore-Tex; WL Gore \& Associates, Flagstaff, Ariz) vascular prosthesis was used to construct the intraventricular conduit rerouting the ventricular septal defect to the aorta, with enlargement of the ventricular septal defect and resecting the hypertrophic muscular bands in the bilateral conus when necessary. Follow-up was made in all patients with a median duration of 93 months (range, 8-140 months).

Results: One patient died during hospitalization and 1 patient died at 8 months after operation, making the mortality $6.5 \%$. The peak pressure gradient across the left ventricular outflow tract was less than $30 \mathrm{~mm} \mathrm{Hg}$ in all patients but 1 $(3.3 \%)$. In the last patient, it increased from $16 \mathrm{~mm} \mathrm{Hg}$ early after operation to $50 \mathrm{~mm} \mathrm{Hg}$ at 7 years follow-up. The peak pressure gradient across the right ventricular outflow tract ranged from 6 to $30 \mathrm{~mm} \mathrm{Hg}$ in all patients. One patient had moderate mitral regurgitation with New York Heart Association class II. One patient had preoperative severe pulmonary arterial hypertension (mean pressure, $50 \mathrm{~mm} \mathrm{Hg}$ ) and was treated with bosentan. Other patients were in New York Heart Association class I.

Conclusions: Biventricular repair with intraventricular conduit is a relatively simple and safe procedure for patients aged more than 2 years with doubleoutlet right ventricle with noncommitted ventricular septal defect, with excellent early and midterm outcomes. (J Thorac Cardiovasc Surg 2020;159:2397-403)

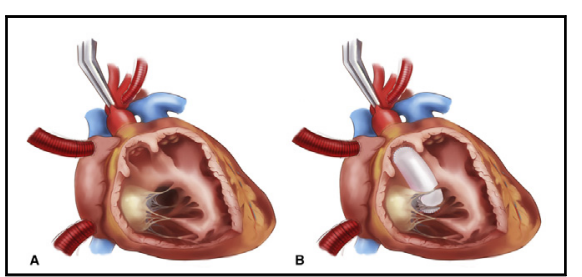

The intraventricular conduit was constructed using a vascular graft to connect the VSD to the aorta.

Central Message

The technique using an intraventricular condui to connect the VSD to the aorta in biventricular repair of DORVncVSD in patients aged more than 2 years had lower mortality and morbidity compared with other techniques.

\section{Perspective}

Biventricular repair with an intraventricular conduit is feasible for patients with DORVncVSD aged more than 2 years, with excellent early and midterm outcomes. It is a relatively simple and safe procedure, and therefore easy to popularize.

See Commentaries on pages 2404 and 2406.

\footnotetext{
From the a Department of Cardiovascular Surgery, The Second Xiangya Hospital, Central South University, Changsha, Hunan, China; and ${ }^{\mathrm{b}}$ The Heart Center, Institute of Pediatrics, Guangzhou Women and Children's Medical Center, Guangzhou Medical University, Guangdong, China.

Contract grant sponsor: Special Project of Hunan Science and Technology Plan, China; Contract grant number: 2019SK1015.

Received for publication May 6, 2019; revisions received June 24, 2019; accepted for publication July 11, 2019; available ahead of print Sept 26, 2019.

Address for reprints: Zhongshi Wu, MD, PhD, Department of Cardiovascular Surgery, The Second Xiangya Hospital, Central South University, No 139 Renmin Rd, Changsha, Hunan, 410011, PR China (E-mail: owenzswu@csu.edu.cn). 0022-5223

Copyright (C) 2019 by The American Association for Thoracic Surgery. Published by Elsevier Inc. This is an open access article under the CC BY-NC-ND license (http:// creativecommons.org/licenses/by-nc-nd/4.0/).

https://doi.org/10.1016/j.jtcvs.2019.07.084
}

Double-outlet right ventricle (DORV) is a particular mode of ventriculo-arterial connection. It exhibits a wide spectrum of anatomic and physiologic variations based on the relationship of the ventricular septal defect (VSD) with

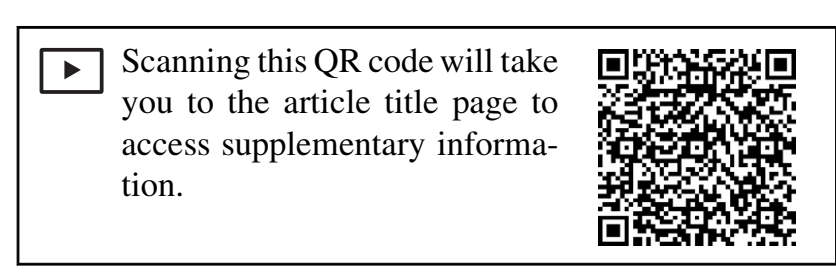




\section{Abbreviations and Acronyms \\ AVSD $=$ atrioventricular septal defect \\ DORV $=$ double-outlet right ventricle \\ DORVncVSD $=$ double-outlet right ventricle with noncommitted ventricular septal defect
LVOT = left ventricular outflow tract
RVOT = right ventricular outflow tract
VSD $\quad=$ ventricular septal defect

the great vessels and the presence or absence of right ventricular outflow tract (RVOT) obstruction. ${ }^{1}$ DORV with noncommitted VSD (DORVncVSD) represents the most extreme form of the anomaly, occurring in $10 \%$ to $20 \%$ of patients with DORV, ${ }^{2,3}$ in which the VSD is located at the distance from both the aortic and pulmonary annuli by a length greater than the aortic diameter and both great vessels arising completely from the right ventricle with bilateral conus. ${ }^{4}$

Biventricular repair is preferred for DORVncVSD, but remains controversial because of the technical challenges and limitations of previously developed surgical procedures. The first is to reroute the VSD to the aorta using a long intraventricular baffle tunnel. ${ }^{5,6}$ This technique may cause potential impairment of the tricuspid and pulmonary valves, and is limited by the presence of the tricuspid chordae and restricted by the distance from the pulmonary artery to tricuspid valve. There is also a high risk of late left ventricular outflow tract (LVOT) obstruction, resulting in cardiac dysfunction and a high reoperation rate. ${ }^{5,7}$ The second is to reroute the VSD to the pulmonary artery with the arterial switch operation as advocated by Lacour-Gayet and colleagues in $2002,{ }^{4}$ but this is not suitable for patients with pulmonary stenosis. The third is double-root translocation as advocated by $\mathrm{Hu}$ and colleagues ${ }^{8}$ for patients with pulmonary stenosis, which is a fairly complex operation.

Another technique that was briefly mentioned but never developed $^{9}$ is using an intraventricular conduit to connect the VSD to the aorta in the biventricular repair of DORVncVSD. It is relatively simple and can be used in patients with DORVncVSD with or without pulmonary stenosis. Therefore, we developed this technique in patients aged more than 2 years. In the present study, we reviewed the early and midterm outcomes of 31 patients undergoing such a procedure since 2006.

\section{PATIENTS AND METHODS \\ Patients}

This study was approved by the Institutional Ethics Committee. Written informed consent was obtained from parents or guardians before surgery to allow the use of their data. Data were prospectively collected in 31
TABLE 1. Demographic and preoperative clinical information of the 31 patients with double-outlet right ventricle with noncommitted ventricular septal defect

\begin{tabular}{|c|c|}
\hline Variable & \\
\hline Male, $\mathrm{n}(\%)$ & $14(45)$ \\
\hline Median age at surgery, y (range) & $5.4(2-23)$ \\
\hline Median weight at surgery, $\mathrm{kg}$ (range) & $16.5(11-58)$ \\
\hline \multicolumn{2}{|l|}{ Age (y), n } \\
\hline$<5$ & 12 \\
\hline$\geq 5$ & 19 \\
\hline \multicolumn{2}{|l|}{ VSD type, $\mathrm{n}$} \\
\hline Perimembranous inlet & 25 \\
\hline Muscular inlet & 6 \\
\hline \multicolumn{2}{|l|}{ Aorta-pulmonary artery alignment, $\mathrm{n}$} \\
\hline Right anterior-left posterior & 22 \\
\hline Left anterior-right posterior & 9 \\
\hline \multicolumn{2}{|l|}{ Associated anomaly, $\mathrm{n}$} \\
\hline Complete atrioventricular septal defect & 3 \\
\hline Coronary artery anomaly & 1 \\
\hline Left superior venous cava & 4 \\
\hline Left juxtaposition of appendages & 1 \\
\hline Patent ductus arteriosus & 7 \\
\hline Pulmonary atresia & 5 \\
\hline Pulmonary stenosis & 15 \\
\hline Pulmonary arterial hypertension & 11 \\
\hline Mild & 6 \\
\hline Moderate & 4 \\
\hline Severe & 1 \\
\hline Secundum atrial septal defect & 10 \\
\hline Tricuspid valve straddling & 1 \\
\hline \multicolumn{2}{|l|}{ Previous surgical procedures, $\mathrm{n}(\%)$} \\
\hline Modified Blalock-Taussig shunt & $2(6.4)$ \\
\hline Pulmonary artery banding & $3(9.6)$ \\
\hline
\end{tabular}

Continuous variables with normal distribution are presented as mean \pm standard deviation, and variables with skewed distribution are presented as median with range. Categoric variables are presented as a frequency and percentage. VSD, Ventricular septal defect.

consecutive patients with DORVncVSD aged more than 2 years undergoing biventricular repair with an intraventricular conduit in the period between May 2006 and January 2018 (Table 1). Among them, 5 patients $(16.1 \%)$ had a palliative procedure before complete repair, including 3 $(9.7 \%)$ with pulmonary artery banding and $2(6.5 \%)$ with a modified Blalock-Taussig shunt.

\section{Clinicopathologic Features}

All patients had a bilateral infundibulum, with a large persistent subaortic conus. Subaortic obstruction was observed in 8 patients in relation with muscle bands inside the subaortic infundibulum. The aortapulmonary artery alignment was right anterior of the aorta and left posterior of the pulmonary artery in 22 patients, and left anterior of aorta and right posterior of the pulmonary artery in 9 patients. The VSD was perimembranous inlet type in 25 patients and muscular inlet type in 6 patients.

The associated lesions are shown in Table 1. A total of 15 patients had pulmonary stenosis, and 5 patients had pulmonary atresia with acceptable branch pulmonary arteries (McGoon value $\geq 1.5$ ). Among 11 patients 
without pulmonary stenosis, 6 had mild pulmonary arterial hypertension (mean pulmonary arterial pressure $22 \pm 4 \mathrm{~mm} \mathrm{Hg}$ ), 4 had moderate pulmonary arterial hypertension $(32 \pm 3 \mathrm{~mm} \mathrm{Hg})$, and 1 had severe pulmonary arterial hypertension $(50 \mathrm{~mm} \mathrm{Hg})$. Three patients had complete atrioventricular septal defect (AVSD).

\section{Surgical Techniques}

General anesthesia was maintained with inhaled isoflurane, intravenous propofol, fentanyl, and pancuronium bromide. The biventricular repair was performed on full-flow cardiopulmonary bypass at moderate hypothermia with repeated crystalloid cardioplegia (Table 2). A right atrial and ventricular incision under the aortic annulus was made. An exploration through the tricuspid orifice and the infundibulum incision allowed the identification of the location of VSD. This was followed by detecting the aorta and pulmonary artery opening position and measuring the shortest and longest distances between the VSD and the aortic annulus. In all patients, as confirmed by preoperative echocardiography, the distance from the superior VSD margin to the aortic valve annulus was equal or longer than the diameter of the aortic valve annulus. Hypertrophic muscular bands in the free wall of bilateral conus were resected.

The restrictive VSD with a diameter less than aortic diameter was enlarged leftward anteriorly, superiorly through the trabecula septomarginalis $(\mathrm{n}=18)$. It was considered crucial to have a VSD diameter $3 \mathrm{~mm}$ larger than the aortic annulus in a cardioplegic heart. The intraventricular conduit was constructed using a polytetrafluoroethylene (Gore-Tex; WL Gore \& Associates, Flagstaff, Ariz) vascular graft, with $16 \mathrm{~mm}$ for patients aged less than 5 years $(\mathrm{n}=12)$ or $19 \mathrm{~mm}$ for those aged 5 years or older $(n=19)$ to connect the left ventricle with the aorta through VSD (Figure 1). Both ends of the graft were trimmed with appropriate inclines (Figure 2), so that the shortest length of the conduit was made equal to the distance between the superior edge of VSD and the inferior edge of the aortic annulus (Figure 2, $d 1$ ), and the longest length to the distance between the inferior edge of VSD and the superior edge of the aortic annulus (Figure 2, d2). The conduit was anastomosed to the rim of VSD with interrupted suture through the tricuspid valve orifice (Figure 3,A) and to the aortic annulus with continuous suture using 4/ 5-0 Prolene through the right ventricular incision (Figure 3, B). For patients with the aorta-pulmonary artery alignment of right anterior-left posterior, the conduit was placed below the conal papillary muscle and then guided upward to the aorta. For those with the aorta-pulmonary artery alignment of left anterior-right posterior, the conduit was placed over the conal papillary muscle. After establishment of the conduit, the tricuspid valve and chordae were carefully checked (Figure 3, C, and Video 1). The tricuspid valve chordae was reimplanted because of conduit extrusion in 3 patients (Table 2).

The RVOT obstruction was treated using an infundibular patch $(\mathrm{n}=9)$ or a transannular patch $(n=8)$. A valved conduit (bovine jugular vein conduit) (Figure $3, D$ ) was used to reconstruct the RVOT for pulmonary atresia $(\mathrm{n}=5)$ or severe stenosis $(\mathrm{n}=1)$. The right ventricular incision was directly sutured in 8 patients (Table 2).

For 3 patients with complete AVSD, atrioventricular valve plasty was performed and the primum atrial septal defect was repaired with a patch. For 1 patient with infundibular stenosis and the anterior descending coronary artery arising from the right coronary artery and crossing the RVOT, the infundibular segment of the coronary artery was carefully dissected, and an autologous pericardium patch was used to widen the RVOT under the coronary artery. Other associated anomalies were treated simultaneously.

All patients were admitted to the cardiac intensive care unit after operation with mechanical ventilation and supported by vasoactive agents (dopamine, epinephrine, norepinephrine, and milrinone) according to our standard protocol. Early death was defined as occurring within 30 days postoperatively.
TABLE 2. Operative and postoperative information of the study $\operatorname{cohort}(\mathbf{n}=31)$

\begin{tabular}{|c|c|}
\hline Operative information & \\
\hline $\mathrm{CPB}$ time $(\mathrm{min})$, mean $\pm \mathrm{SD}$ & $163.4 \pm 45.6$ \\
\hline ACC time $(\min )$, mean \pm SD & $109.1 \pm 30.9$ \\
\hline $\begin{array}{l}\text { Polytetrafluoroethylene (Gore-Tex; WL Gore } \\
\text { \& Associates, Flagstaff, Ariz) conduits } \\
16 \mathrm{~mm}, \mathrm{n}(\%)\end{array}$ & $12(38.7)$ \\
\hline Gore-Tex conduits $19 \mathrm{~mm}, \mathrm{n}(\%)$ & $19(61.3)$ \\
\hline VSD enlargement, $\mathrm{n}(\%)$ & $18(58.1)$ \\
\hline $\begin{array}{l}\text { RVOT treatment, } \mathrm{n}(\%) \\
\text { Infundibular patch } \\
\text { Trans-annular patch } \\
\text { Valved conduits } \\
\text { Direct suture }\end{array}$ & $\begin{array}{l}9(29.0) \\
8(25.8) \\
6(19.4) \\
8(25.8)\end{array}$ \\
\hline $\begin{array}{l}\text { Associated procedures } \\
\text { Tricuspid valve chordae reimplantation, n } \\
\quad(\%) \\
\text { Atrioventricular valve plasty, } \mathrm{n}(\%)\end{array}$ & $\begin{array}{l}3(9.7) \\
3(9.7)\end{array}$ \\
\hline $\begin{array}{l}\text { Postoperative information } \\
\text { Mechanical ventilation time (d) } \\
\text { CICU stay (d) } \\
\text { Postoperative hospital stay (d) }\end{array}$ & $\begin{array}{l}3.9(0.5-15) \\
6(1-20) \\
20(8-62)\end{array}$ \\
\hline $\begin{array}{l}\text { Major postoperative complications, } \mathrm{n}(\%) \\
\text { Complete atrioventricular block } \\
\text { Bleeding requiring unplanned reoperation } \\
\text { ECMO circulatory support } \\
\text { Renal failure requiring temporary dialysis }\end{array}$ & $\begin{array}{l}1(3.2) \\
2(6.4) \\
1(3.2) \\
1(3.2)\end{array}$ \\
\hline Peak PG across LVOT on discharge $(\mathrm{mm} \mathrm{Hg})$ & $8.7 \pm 6.3$ \\
\hline Peak PG across LVOT at follow-up ( $\mathrm{mm} \mathrm{Hg}$ ) & $9.4 \pm 9.6$ \\
\hline Peak PG across RVOT on discharge ( $\mathrm{mm} \mathrm{Hg}$ ) & $15.5 \pm 11.2$ \\
\hline Peak PG across RVOT at follow-up (mm Hg) & $15.8 \pm 12.5$ \\
\hline
\end{tabular}

Continuous variables with normal distribution are presented as mean $\pm \mathrm{SD}$, and variables with skewed distribution are presented as median with range. Categoric variables are presented as a frequency and percentage. $C P B$, Cardiopulmonary bypass; $S D$, standard deviation; $A C C$, aortic crossclamping; $V S D$, ventricular septal defect; $R V O T$, right ventricular outflow tract; $C I C U$, cardiac intensive care unit; $E C M O$, extracorporeal membrane oxygenation; $P G$, pressure gradient; $L V O T$, left ventricular outflow tract.

\section{Follow-up}

Annual follow-up was made in all patients. The peak pressure gradient across the LVOT and RVOT was measured using echocardiography (Figure 4). The left ventricular function was evaluated by measuring the left ventricular ejection fraction using the Simpson method with the values less than $50 \%$ indicating dysfunction. Death and reoperation were recorded.

\section{Statistical Analysis}

Continuous variables with normal distribution are presented as mean \pm standard deviation, and variables with skewed distribution are presented as median with range. Categoric variables are presented as a frequency and percentage. Data were analyzed using SPSS 22.0 (SPSS Inc, Chicago, Ill). 


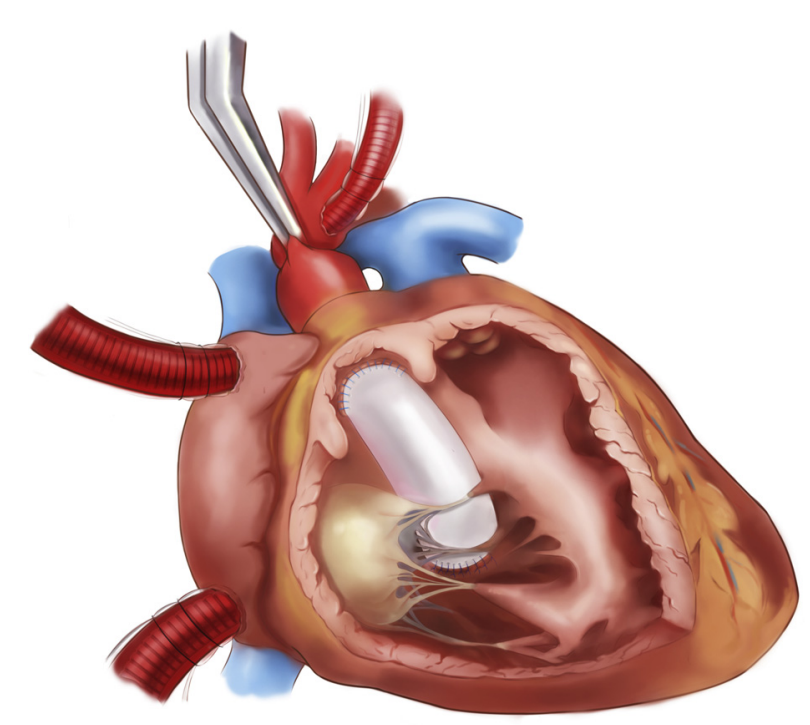

FIGURE 1. Schematic diagram of biventricular repair by intraventricular conduit.

\section{RESULTS \\ Early Outcomes}

There was 1 death during the cardiac intensive care unit stay, making the early mortality $3.2 \%$. This patient with complete AVSD had third-degree atrioventricular block requiring pacemaker implantation and severe mitral valve insufficiency, and died 2 days after the operation. Major postoperative complications occurred in another 4 patients (Table 2). Two of them had unplanned reoperations for drainage of hemorrhagic cardiac tamponade. One who had severe pulmonary stenosis and received a valved conduit to reconstruct RVOT required ECMO because of low cardiac output syndrome on the operation day and was successfully weaned from ECMO 4 days later. The remaining patient had renal failure requiring temporary dialysis on the operation day.

Among the 30 survivors, the durations of mechanical ventilation, cardiac intensive care unit stay, and hospital stay are shown in Table 2 . The left ventricular ejection fraction ranged from $60 \%$ to $85 \%$ before hospital discharge in all patients. One patient who was 7 years old at operation and had a mean pulmonary arterial pressure of $50 \mathrm{~mm} \mathrm{Hg}$ was treated with bosentan at the time of discharge. The peak pressure gradient across the LVOT was $20 \mathrm{~mm} \mathrm{Hg}$ or less in 28 patients and 21 to $28 \mathrm{~mm} \mathrm{Hg}$ in 2 patients. The peak pressure gradient across the RVOT ranged from 6 to $30 \mathrm{~mm} \mathrm{Hg}$, and the pulmonary valves showed no or mild regurgitation in all patients. The tricuspid valves showed no or mild regurgitation in 25 patients and moderate regurgitation in 5 patients without stenosis.

\section{Follow-up Results}

Patients were followed up with a median duration of 93 months (range, 8-140 months). One patient died of infective endocarditis with vegetation-caused LVOT obstruction 8 months after the operation, making the late mortality $3.3 \%$. No late reoperation was required. The left ventricular ejection fraction ranged from $50 \%$ to $75 \%$ in the 29 survivors. Among them, 26 were in NYHA functional class I. In the 3 patients in NYHA class II, 1 had severe mitral valve incompetence preoperatively and underwent valvuloplasty, but still had moderate mitral regurgitation after operation and was given digoxin. One patient ( 7 years old at operation) had severe pulmonary arterial hypertension (mean pressure, $50 \mathrm{~mm} \mathrm{Hg}$ ) before operation, which decreased to $38 \mathrm{~mm} \mathrm{Hg}$ after bosentan treatment for 3 years.

The peak pressure gradient across the LVOT was less than $30 \mathrm{~mm} \mathrm{Hg}$ in all patients but $1(3.3 \%)$. In the last patient
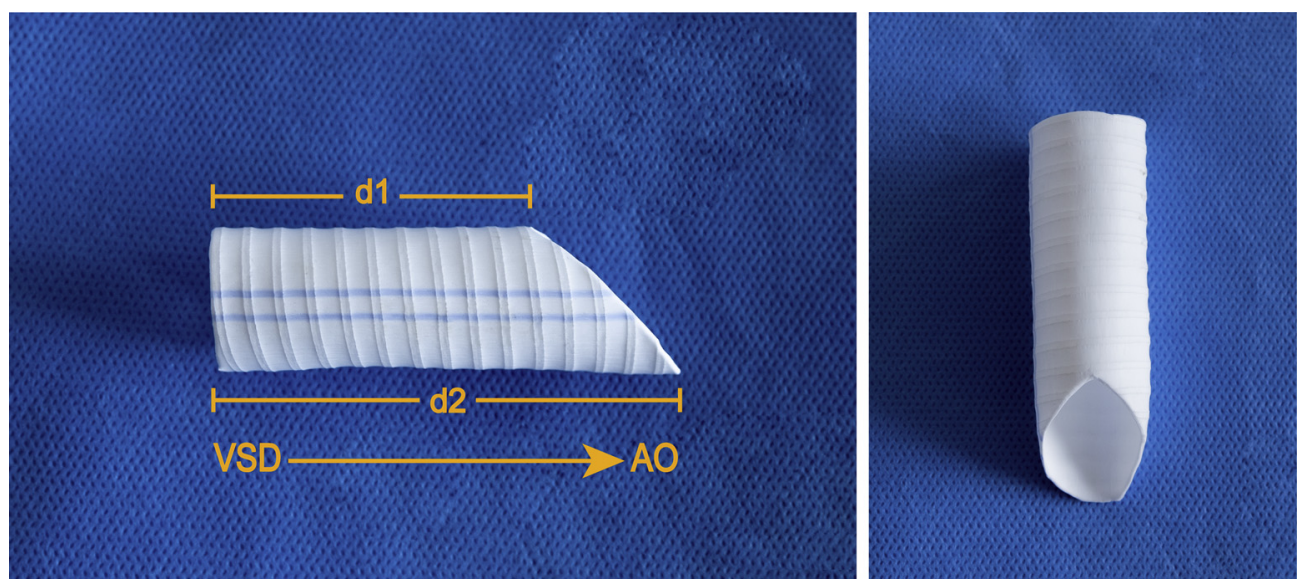

FIGURE 2. Schematic diagram of intraventricular conduit. The shortest length is equal to the distance between the superior edge of the VSD and the inferior edge of the aortic annulus $(d 1)$. The longest length of the conduit is equal to the distance between the inferior edge of the VSD and the superior edge of the aortic annulus $(d 2)$. VSD, Ventricular septal defect; $A O$, aorta. 

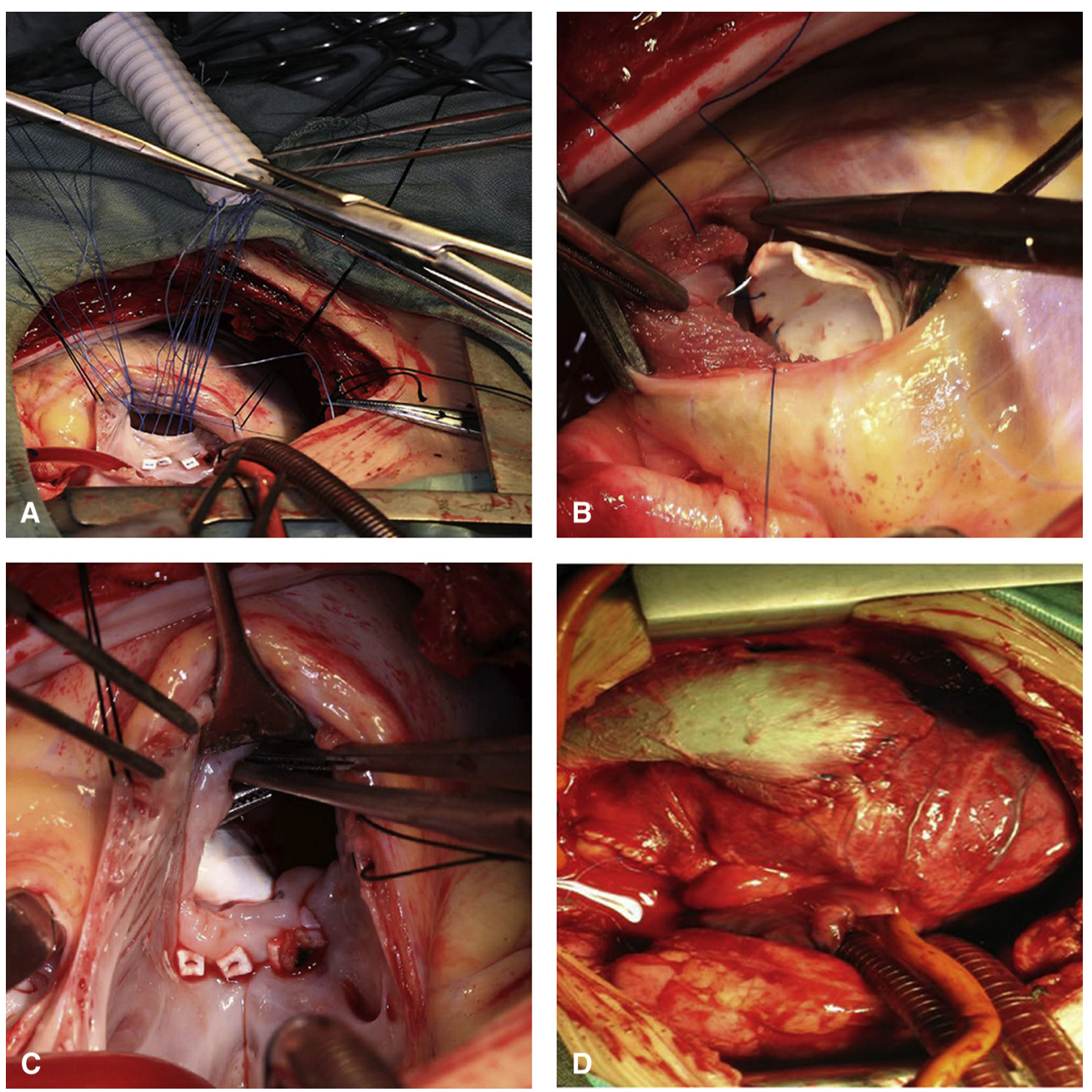

FIGURE 3. A, Polytetrafluoroethylene (Gore-Tex; WL Gore \& Associates, Flagstaff, Ariz) vascular prosthesis was used for the patients. The defect end was anastomosed with interrupted suture. B, The aortic end was anastomosed with continuous suture. C, After the establishment of the conduit, the tricuspid valves and chordae were carefully checked. D, Valved conduit (bovine jugular vein conduit) was used to reconstruct RVOT for pulmonary atresia.

(9 years old at operation), this gradient increased from $16 \mathrm{~mm} \mathrm{Hg}$ early after operation to $50 \mathrm{~mm} \mathrm{Hg}$ at 7 years follow-up; the patient is currently awaiting reoperation. Five patients had mild aortic valve regurgitation. The peak pressure gradient across the RVOT ranged from 6 to $30 \mathrm{~mm} \mathrm{Hg}$ in all patients. Among 8 patients who were treated with a transpulmonary valve annular patch, 4 had mild pulmonary regurgitation, and 4 had moderate pulmonary regurgitation. The tricuspid valve regurgitation was absent or mild in 25 patients and moderate in 4 patients. No tricuspid valve stenosis was observed.

\section{DISCUSSION}

The present cohort study demonstrated that the technique of biventricular repair using an intraventricular conduit to reroute the VSD to the aorta for DORVncVSD is relatively simple with favorable early and midterm outcomes. In our series of 31 patients, there was 1 early and 1 late mortality.
There were no major complications or required reoperations at midterm follow-up.

Biventricular repair of DORVncVSD is preferred but remains challenging. The several different techniques that have evolved are still associated with high mortality, major complications, and high risk of reoperation. The most common technique is to use a long intraventricular baffle tunnel to reroute the VSD to the aorta. Belli and colleagues ${ }^{5}$ reported that among a series of 21 patients, the early mortality was $10 \%$ without late death, and 6 patients $(29 \%)$ underwent reoperations due to late subaortic stenosis. BarberoMarcial and colleagues ${ }^{6}$ reported that among 18 patients undergoing this procedure with multiple patches, the inhospital mortality was $11 \%$ and late mortality was $16.6 \%$. There was no late subaortic stenosis. In a series of 40 patients, $\mathrm{Li}$ and colleagues ${ }^{10}$ reported the in-hospital mortality was $12.5 \%$, early intraventricular baffle obstruction was present in $4(11.4 \%)$, late obstruction was present 


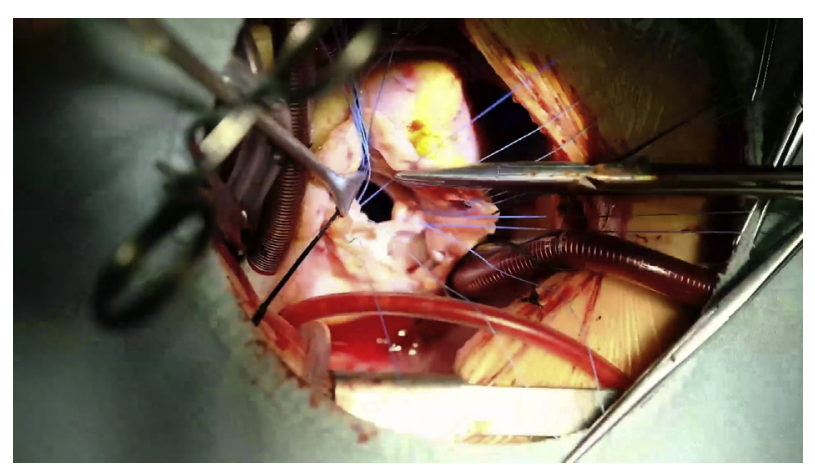

VIDEO 1. The surgical procedure of biventricular repair of DORVncVSD using an intraventricular conduit. Video available at: https://www.jtcvs.org/article/S0022-5223(19)31637-X/fulltext.

in $6(17.1 \%)$, and $3(8.6 \%)$ required reoperation. Obviously, the intraventricular baffle manipulation is complex, and LVOT obstruction is the main complication and cause of reoperation, ${ }^{11,12}$ with greater risks of the longer tunnel. ${ }^{4,10}$ Furthermore, the intraventricular tunnel inevitably creates unfavorable hemodynamic effects and flow turbulence $e^{6-8}$ as a result of the akinetic area induced by stitching the long patch to the left ventricular myocardium, impairing the left ventricular function. ${ }^{4,7}$ It might cause the impairment of the tricuspid chordae tendineae and papillary muscle, which may block the passageway of the tunnel. ${ }^{6}$

Another technique is to construct an intraventricular baffle tunnel to reroute the VSD to the pulmonary artery with the arterial switch operation. $\mathrm{Li}$ and colleagues ${ }^{10}$ reported $1(2.9 \%)$ in-hospital death and $3(8.8 \%)$ late deaths among 35 patients. Lacour-Gayet and colleagues ${ }^{4}$ reported $1(10 \%)$ extracardiac death and no late death or reoperation among 10 patients at a mean follow-up of 20 months. This technique simplifies the intraventricular maneuver and decreases the risk of LVOT obstruction. However, this technique has its limitations. First, it is not suitable for patients with pulmonary stenosis. Second, the arterial switch requires translation of the coronary arteries. This is particularly a problem in patients with aberrant origins of coronary arteries, for example, a single coronary artery with the left branch running behind the pulmonary artery. ${ }^{4}$

$\mathrm{Hu}$ and colleagues ${ }^{8}$ recently proposed the double root translocation technique for the repair of DORVncVSD with pulmonary stenosis. However, this technique is complex and difficult to popularize.

In comparison, the intraventricular conduit technique developed by us has a number of advantages. First, it is a relatively simple procedure and easy to popularize. Second, it can avoid complicated manipulation between the conal papillary muscle and chordae of the tricuspid valve, thus preventing impairing the tricuspid and pulmonary valves. Third, it is suitable for patients with pulmonary stenosis, which is common in DORVncVSD ( $\mathrm{n}=15$ in our cohort). Fourth, it may protect left ventricular function by reducing the interventricular septal injury and avoiding the significant akinetic area and flow turbulence in LVOT as seen in the baffle tunnel repair. Fifth, this technique did not require translation of the coronary arteries. ${ }^{4}$ These advantages may
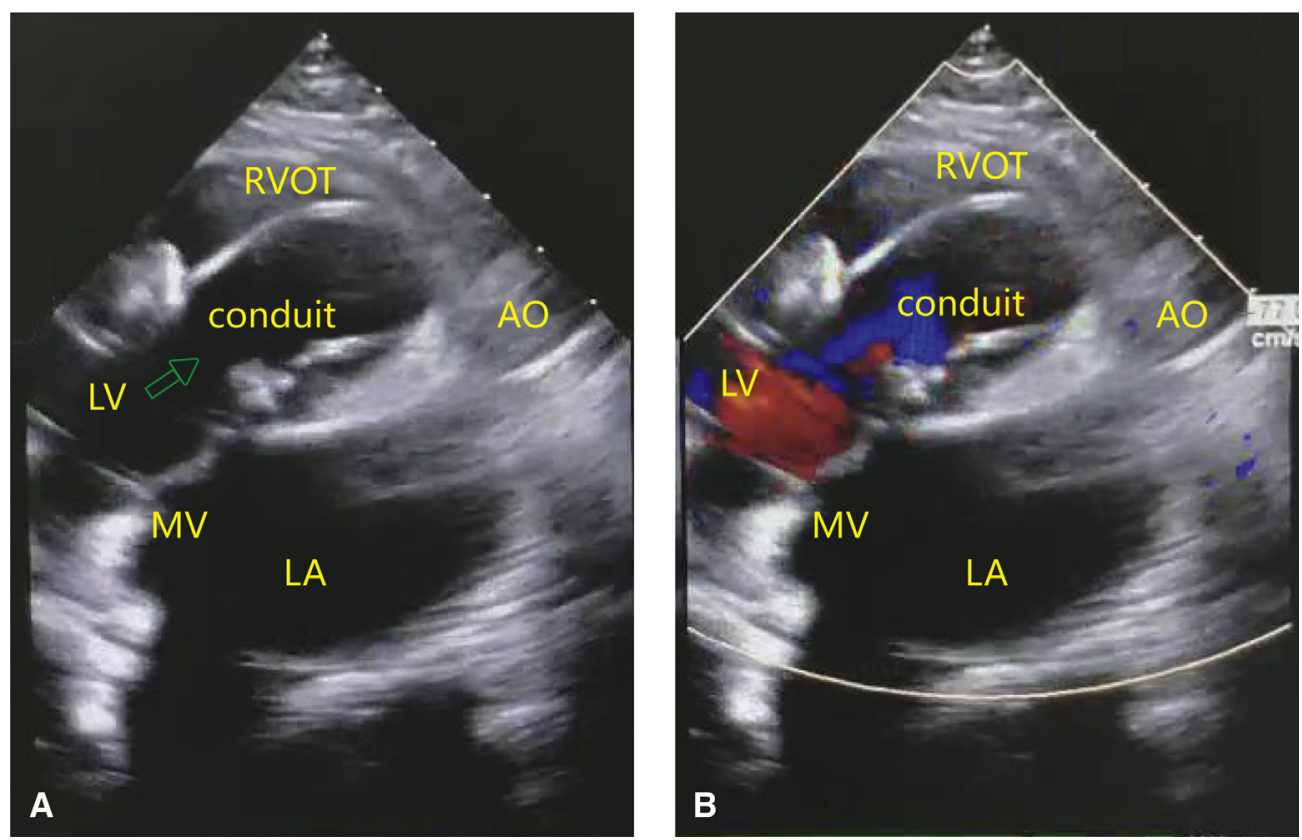

FIGURE 4. Postoperative intraventricular conduit was assessed by 2-dimensional ultrasound (A) and color Doppler ultrasound (B). RVOT, Right ventricular outflow tract; $A O$, aorta; $L V$, left ventricle; $M V$, mitral valve; $L A$, left atrium. 
have been the reason for the low mortality and morbidity in our cohort.

Some details should be provided about our technique. First, a restrictive VSD is commonly seen in DORVncVSD. ${ }^{4,5}$ Therefore, VSD enlargement is usually an integral part of this technique to allow unobstructed egress from the left ventricle. ${ }^{11,13}$ In our series of 31 patients, $18(58 \%)$ had VSD enlargement and no obstruction occurred. In our experience, it is crucial to have a VSD diameter $3 \mathrm{~mm}$ larger than the aortic annulus on a cardioplegic heart. Second, this technique is indicated for patients aged more than 2 years and weighing $10 \mathrm{~kg}$, in whom the right ventricular cavity is sufficient to place a conduit suitable for later growth and development. Third, we recommend the use of a $\geq 16-\mathrm{mm}$ conduit for patients aged less than 5 years (the $16-\mathrm{mm}$ conduit is the maximal size for a 2-year-old child) and a $\geq 19$-mm conduit for patients aged more than 5 years. It is sensible to choose a larger conduit for some patients with a bigger ventricular cavity. Third, for patients who may develop severe pulmonary arterial hypertension, pulmonary artery banding in the early stage of life is necessary. Fourth, for patients with severe RVOT obstruction, a systemic-topulmonary shunt should be performed in the early stage of life to promote pulmonary artery development and alleviate the symptoms of hypoxia.

Clearly, the latter 2 palliative procedures are routine practice in advanced centers and countries, but they were not available until 2011 in our center. Furthermore, among 11 patients without pulmonary stenosis, 6 developed mild pulmonary arterial hypertension, 4 developed moderate pulmonary arterial hypertension, and 1 developed severe pulmonary arterial hypertension (mean pulmonary arterial pressure $50 \mathrm{~mm} \mathrm{Hg}$ ) before operation. The clinical management problems that our patients encountered, such as late referral, older age at operation, lack of palliative procedure, and development of pulmonary arterial hypertension, represent the current situation in the developing countries. ${ }^{8,10}$

\section{Study Limitations}

The unavoidable question of the novel technique is its limitation in the application in younger patients. Along the same line, because the conduit does not grow to meet children's growth, longer-term and close follow-up is required to examine any potential development of conduit obstruction. A close follow-up is particularly important because 1 of our patients died of infective endocarditis with vegetation-caused LVOT obstruction 8 months after the operation. Additionally, we only examined left ventricular systolic function. The advantages of this technique in terms of intra-conduit hemodynamics remain speculative, which needs further studies with detailed assessments of systolic and diastolic function of both ventricles.

\section{CONCLUSIONS}

Biventricular repair with intraventricular conduit is a relatively simple and safe procedure for patients aged more than 2 years who have DORVncVSD, with excellent early and midterm outcomes. Further studies are warranted to evaluate the long-term outcomes.

\section{Conflict of Interest Statement}

Authors have nothing to disclose with regard to commercial support.

The authors thank Dr Francois Lacour-Gayet for constructive review of the article.

\section{References}

1. Walters HL, Mavroudis C, Tchervenkov CI, Jacobs JP, Lacour-Gayet F, Jacobs ML. Congenital heart surgery nomenclature and database project: double outlet right ventricle. Ann Thorac Surg. 2000;69(4 Suppl):S249-63.

2. Kirklin JW, Pacifico AD, Blackstone EH, Kirklin JK, Bargeron LM Jr. Current risks and protocols for operations for double-outlet right ventricle. Derivation from an 18 year experience. J Thorac Cardiovasc Surg. 1986;92:913-30.

3. Musumeci F, Shumway S, Lincoln C, Anderson RH. Surgical treatment for double-outlet right ventricle at the Brompton Hospital, 1973 to 1986. J Thorac Cardiovasc Surg. 1988;96:278-87.

4. Lacour-Gayet F, Haun C, Ntalakoura K, Belli E, Houyel L, Marcsek P, et al. Biventricular repair of double outlet right ventricle with non-committed ventricular septal defect (VSD) by VSD rerouting to the pulmonary artery and arterial switch. Eur J Cardiothorac Surg. 2002;21:1042-8.

5. Belli E, Serraf A, Lacour-Gayet F, Hubler M, Zoghby J, Houyel L, et al. Doubleoutlet right ventricle with non-committed ventricular septal defect. Eur J Cardiothorac Surg. 1999;15:747-52.

6. Barbero-Marcial M, Tanamati C, Atik E, Ebaid M. Intraventricular repair of double-outlet right ventricle with noncommitted ventricular septal defect: advantages of multiple patches. J Thorac Cardiovasc Surg. 1999;118: 1056-67.

7. Belli E, Serraf A, Lacour-Gayet F, Inamo J, Houyel L, Bruniaux J, et al. Surgical treatment of subaortic stenosis after biventricular repair of doubleoutlet right ventricle. J Thorac Cardiovasc Surg. 1996;112:1570-8; discussion $1578-80$.

8. Hu S, Xie Y, Li S, Wang X, Yan F, Li Y, et al. Double-root translocation for double-outlet right ventricle with noncommitted ventricular septal defect or double-outlet right ventricle with subpulmonary ventricular septal defect associated with pulmonary stenosis: an optimized solution. Ann Thorac Surg. 2010;89: 1360-5.

9. Stark J, de Leval M, Tsang VT. Chapter 32: Double-outlet right ventricle. In: Surgery for Congenital Heart Defects. 3rd ed. Chichester, England: John Wiley and Sons Ltd; 2006:435-42.

10. Li S, Ma K, Hu S, Hua Z, Yan J, Pang K, et al. Biventricular repair for double outlet right ventricle with non-committed ventricular septal defect. Eur J Cardiothorac Surg. 2015;48:580-7; discussion 587.

11. Villemain O, Bonnet D, Houyel L, Vergnat M, Ladouceur M, Lambert V, et al. Double-outlet right ventricle with noncommitted ventricular septal defect and 2 adequate ventricles: is anatomical repair advantageous. Semin Thorac Cardiovasc Surg. 2016;28:69-77.

12. Villemain O, Belli E, Ladouceur M, Houyel L, Jalal Z, Lambert V, et al. Impact of anatomic characteristics and initial biventricular surgical strategy on outcomes in various forms of double-outlet right ventricle. J Thorac Cardiovasc Surg. 2016; 152:698-706.

13. Lacour-Gayet F. Intracardiac repair of double outlet right ventricle. Semin Thorac Cardiovasc Surg Pediatr Card Surg Annu. 2008;39-43.

Key Words: biventricular repair, double-outlet right ventricle, intraventricular conduit, noncommitted ventricular septal defect 